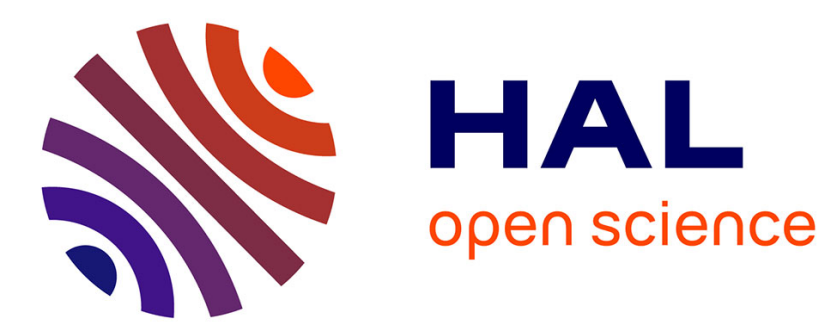

\title{
Resonant character of laser-induced formation of particles in a Cs-H 2 vapour
}

\author{
J.L. Picqué, J. Verges, R. Vetter
}

\section{To cite this version:}

J.L. Picqué, J. Verges, R. Vetter. Resonant character of laser-induced formation of particles in a Cs-H 2 vapour. Journal de Physique Lettres, 1980, 41 (13), pp.305-308. 10.1051/jphyslet:019800041013030500 . jpa-00231785

\section{HAL Id: jpa-00231785 https://hal.science/jpa-00231785}

Submitted on 1 Jan 1980

HAL is a multi-disciplinary open access archive for the deposit and dissemination of scientific research documents, whether they are published or not. The documents may come from teaching and research institutions in France or abroad, or from public or private research centers.
L'archive ouverte pluridisciplinaire HAL, est destinée au dépôt et à la diffusion de documents scientifiques de niveau recherche, publiés ou non, émanant des établissements d'enseignement et de recherche français ou étrangers, des laboratoires publics ou privés. 


\title{
Resonant character of laser-induced formation of particles in a $\mathrm{Cs}-\mathrm{H}_{2}$ vapour
}

\author{
J. L. Picqué, J. Vergès and R. Vetter \\ Laboratoire Aimé-Cotton $\left({ }^{*}\right)$, Centre National de la Recherche Scientifique, Bâtiment 505, 91405 Orsay, France \\ (Reçu le 9 avril 1980, accepté le 16 mai 1980)
}

\begin{abstract}
Résumé. - On montre que la formation de particules induite par laser dans une vapeur $\mathrm{Cs}-\mathrm{H}_{2}$ est résonnante vis-àvis des secondes raies de résonance du césium atomique. On explique l'existence d'un seuil pour la longueur d'onde du laser à l'aide de considérations énergétiques simples relatives à la réaction primaire de formation de molécules de $\mathrm{CsH}$. L'étude de la fluorescence de ces molécules induite par laser suggère que des mécanismes de réaction autres que l'excitation directe des atomes de Cs dans le niveau 7P peuvent également intervenir.
\end{abstract}

\begin{abstract}
Observation of laser-induced formation of particles in a Cs- $\mathrm{H}_{2}$ vapour is found to be resonant with the second resonance lines of cesium atoms. The existence of a threshold for laser wavelength is explained by help of simple energy considerations applying to the primary reaction of formation of $\mathrm{CsH}$ molecules. Study of the laser-induced fluorescence of these molecules suggests that other reaction mechanisms than direct excitation of Cs atoms to the 7P level may also take place.
\end{abstract}

It was shown in 1975 by Tam, Moe and Happer that formation of micron-sized visible particles (laser snow) can be observed in a cell filled with cesium and hydrogen, when irradiated by an intense laser beam of suitable wavelength [1]. The phenomenon was interpreted in terms of initial formation of $\mathrm{CsH}$ molecules, which in turn agregate to form $\mathrm{CsH}$ crystals. Recently, this crystal formation was explained through a thermodynamical approach [2]. Concerning the initial production of cesium hydride molecules, Tam et al. proposed several mechanisms involving excited atomic or molecular species $[1,3]$. In this Letter, we report experiments aimed to distinguish among these mechanisms. In particular, we show that particle formation is enhanced when the laser radiation is tuned to the second resonance lines $6 \mathrm{~S} \rightarrow 7 \mathrm{P}$ of atomic cesium. This resonant character confirms the feasibility, which was also pointed out in the case of $\mathrm{UF}_{6}$ molecules [4], of isotope separation by the present phenomenon [1]. However, from the study of the dependence of laser-induced fluorescence of $\mathrm{CsH}$ molecules on laser intensity, we infer that other reaction mechanisms may exist at large radiation intensities.

In the original experiment of Tam et al. [1], the cell contained $\mathrm{Cs}$ and $\mathrm{H}_{2}$ at relatively high pressure (a fraction of atmosphere) and was heated at about

$\left(^{*}\right)$ Laboratoire associé à l’Université Paris-Sud. $350^{\circ} \mathrm{C}$. It was irradiated by a powerful laser beam (hundreds of milliwatts) provided by an $\mathrm{Ar}^{+}$laser oscillating at 454.5 or $457.9 \mathrm{~nm}$. The proposed explanation of the experiment was that pressure broadening of the second resonance lines at 455.5 or $459.3 \mathrm{~nm}$ allowed a substantial pumping of $\mathrm{Cs}$ atoms from the ground state to the $7{ }^{2} \mathrm{P}_{3 / 2}$ or $7{ }^{2} \mathrm{P}_{1 / 2}$ state, respectively. Excited Cs atoms could then react efficiently with hydrogen to form $\mathrm{CsH}$ molecules, which could further condensate and give rise to particles. Therefore, in that experiment, hydrogen acted both as a buffer gas and a reactive one.

In our experiment, we have investigated the possibility of particle formation by use of a C.W. dye laser which we tuned in the vicinity of the $6 \mathrm{~S} \rightarrow 6 \mathrm{P}$ and $6 \mathrm{~S} \rightarrow 7 \mathrm{P}$ resonance doublets, in the near infrared and blue region, respectively. Experiments have given negative results (this will be explained later) in the first case, but have led to particle formation in the second case. Thanks to the tunability of the laser, hydrogen was only involved as a reagent, so that it was possible to reduce considerably the gas pressure in the cell (at the working temperature of $350^{\circ} \mathrm{C}$, pressures of $\mathrm{Cs}$ and $\mathrm{H}_{2}$ were both around 7 torr). Also due to the observed resonant behaviour, we could obtain particle formation for small values of the laser output (10 $\mathrm{mW}$ typically).

The experimental arrangement is schematically shown in figure 1 . The unfocussed beam $(2 \mathrm{~mm}$ diameter) from the dye laser crossed the cylindrical 


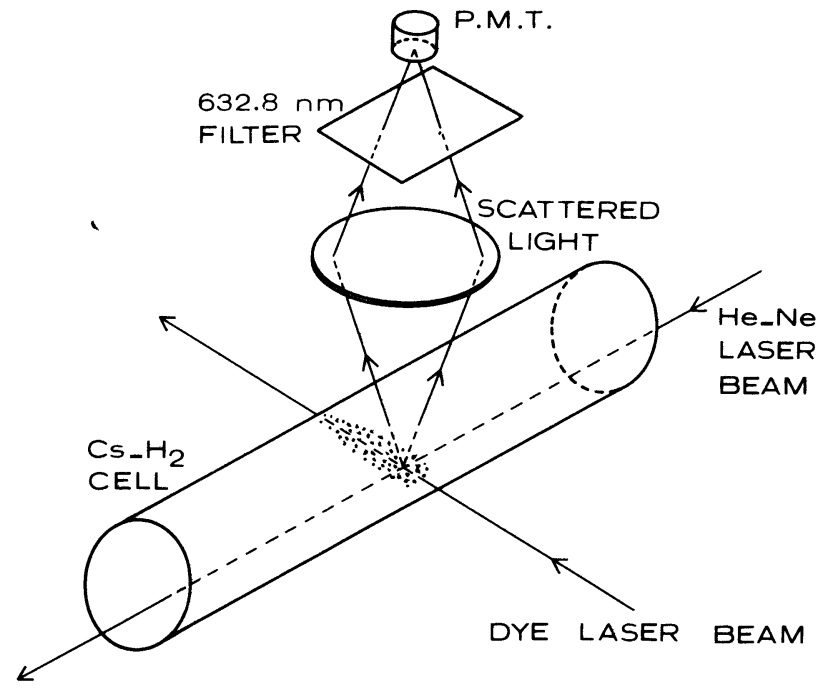

Fig. 1. - Experimental arrangement for the observation, by Mie scattering of a He-Ne laser beam, of particles formed in the dye laser beam. The cell is placed inside a transparent glass oven.

gas cell, made of alkali-resistant glass (Corning 1720). The C.W. dye laser was multimode (linewidth of about $0.02 \mathrm{~nm}$ ) and delivered a maximum power of $170 \mathrm{~mW}$ in the blue region. Particles were observed by Mie scattering of an auxiliary He-Ne laser beam propagating perpendicularly to the dye laser one. In order to monitor a region in which the particle formation is efficient enough, the He-Ne probe laser beam was located near the entrance wall of the cell, where the active dye laser beam is not yet completely absorbed. The scattered light was collected at right angle and focussed onto the cathode of a photomultiplier tube preceded by a suitable interference filter. Figure 2 shows the intensity of the scattered light as a function of the dye laser wavelength. The wavelength was scanned continuously between $455.0 \mathrm{~nm}$ and $460.0 \mathrm{~nm}$ by rotating a Lyot filter inside the cavity

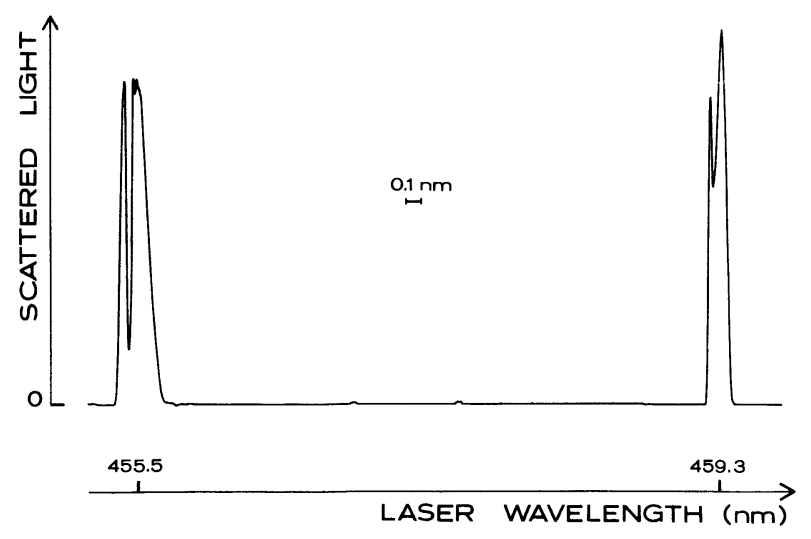

Fig. 2. - Experimental recording of the intensity of the light scattered by laser-induced particles versus dye laser wavelength. of the dye laser. We have verified, by use of a grating spectrometer, that the two observed profiles are centred on the components $6{ }^{2} \mathrm{~S}_{1 / 2} \rightarrow 7^{2} \mathrm{P}_{1 / 2}$ and $6{ }^{2} \mathrm{~S}_{1 / 2} \rightarrow 7{ }^{2} \mathrm{P}_{3 / 2}$, respectively, of the second resonance doublet. Their shape is, of course, most influenced by the high density of Cs atoms at the working temperature. They exhibit a hole which probably results from partial absorption of the dye laser beam before reaching the observation zone. The large width $(\sim 0.1 \mathrm{~nm})$ and the asymmetry of the two profiles should mainly arise from the resonance broadening phenomenon [5].

Since particle formation occurs through the primary reaction

$$
\mathrm{Cs}^{*}(7 \mathrm{P})+\mathrm{H}_{2} \rightarrow \mathrm{CsH}+\mathrm{H},
$$

we have found of interest, in a second step, to study the laser-induced fluorescence (L.I.F.) of the product $\mathrm{CsH}$ molecules. This was performed by irradiating the cell at $455.5 \mathrm{~nm}$ with the beam from the dye laser, the large linewidth of which allowed us to induce both : (i) formation of $\mathrm{CsH}$ molecules in their ground state $\mathrm{X}^{1} \Sigma^{+}$through reaction (1), (ii) subsequent excitation of these molecules to the first electronic excited state $\mathrm{A}^{1} \Sigma^{+}[6]$. The experimental set-up was similar to the one shown in figure 1, except that the $\mathrm{He}-\mathrm{Ne}$ laser beam was removed, and that fluorescence light was observed instead of scattered light. For this experiment, the dye laser beam was focussed (to about $0.1 \mathrm{~mm}$ diameter) near the entrance wall of the cell, thus producing a bright red fluorescent zone, the image of which was formed on the cathode of a photomultiplier tube. This fluorescent light, visible to the naked eye, appears only when the dye laser is tuned to the lines of the second resonance doublet. This ensures that it does come from $\mathrm{CsH}$ molecules. However, in order to limit the collection of background fluorescence from $\mathrm{Cs}_{2}$ molecules, we selected the light emitted around $620 \mathrm{~nm}$ by use of an interference filter with a $10 \mathrm{~nm}$ bandwidth. Figure 3 shows the dependence of the fluorescence signal on the laser radiation intensity $I$ in the power range $10-170 \mathrm{~mW}$. One observes a $I^{3 / 2}$ law, already reported in ref. [1], in the low intensity range (power $\lesssim 100 \mathrm{~mW}$ ), and a more rapid variation at higher intensities.

The reaction of ground state cesium atoms with molecular hydrogen is by far endoergic. The energy defect corresponds approximately to the difference, $2.4 \mathrm{eV}$, between the binding energy of the $\mathrm{H}_{2}$ reagent molecule, $4.48 \mathrm{eV}$ [7], and that of the $\mathrm{CsH}$ product molecule, $2.08 \mathrm{eV}$ [6]. This appears clearly on figure 4, which displays the energy levels of reagents and products. It shows that the energy of the

$$
\mathrm{Cs}^{*}(7 \mathrm{P})+\mathrm{H}_{2}\left(v^{\prime \prime}=0\right)
$$

system is approximately equal to that of the low-lying rovibrational levels of the electronic ground state $\mathrm{X}^{1} \Sigma^{+}$of the $\mathrm{CsH}$ molecule. On the contrary, the 


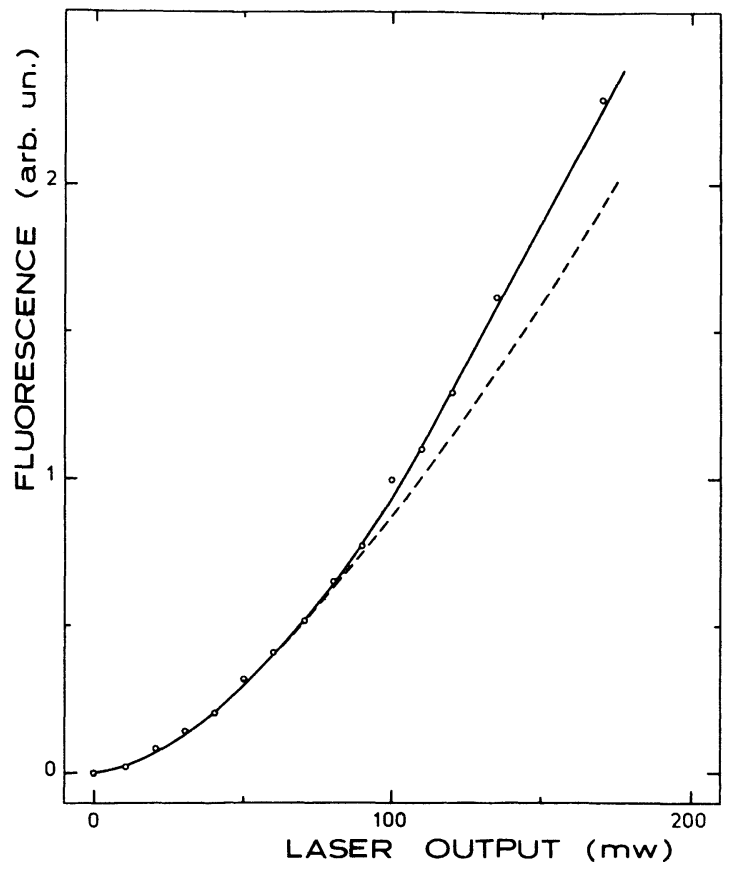

Fig. 3. - Intensity of laser-induced fluorescence of $\mathrm{CsH}$ molecules versus incident $455.5 \mathrm{~nm}$ laser intensity $I$. The dotted line represents a $I^{3 / 2}$ law. The horizontal scale is graduated in terms of the power carried in the laser beam. lower levels of Cs atoms lie below the energy threshold of the reaction. This is the case for the $7 \mathrm{~S}$ and $5 \mathrm{D}$ levels, which are populated through radiative decay from the 7P level. This is even more obvious for the 6P level, explaining why we could not induce particle formation by tuning the laser to the lines of the first resonance doublet. Note that vibrational activation of the reaction would require excitation of the $\mathrm{H}_{2}$ molecules to $v^{\prime \prime} \geqslant 5$, which is not possible under our experimental conditions. It also appears on figure 4 that the first electronic excited state $\mathrm{A}^{1} \Sigma^{+}$of $\mathrm{CsH}$ molecules is not very far (about $0.75 \mathrm{eV}$ ) above the ionization limit of Cs atoms. Thus, especially if some additional energy is provided to the reactants (e.g., through vibrational excitation of $\mathrm{H}_{2}$ molecules to $v^{\prime \prime} \geqslant 2$ ), excited $\mathrm{CsH}$ molecules in the A state could be produced from $\mathrm{Cs}$ atoms in highly excited levels.

A further insight into the processes which actually occur in our experiments can be gained from the analysis of the dependence of the laser-induced fluorescence of $\mathrm{CsH}$ molecules on the incoming radiation intensity $I$. Let $n(I)$ be the number of excited Cs atoms in the $7 \mathrm{P}$ state in steady-state regime. This quantity varies according to the general saturation law

$$
n(I)=\frac{n_{0}}{2} \frac{\xi I}{1+\xi I}
$$

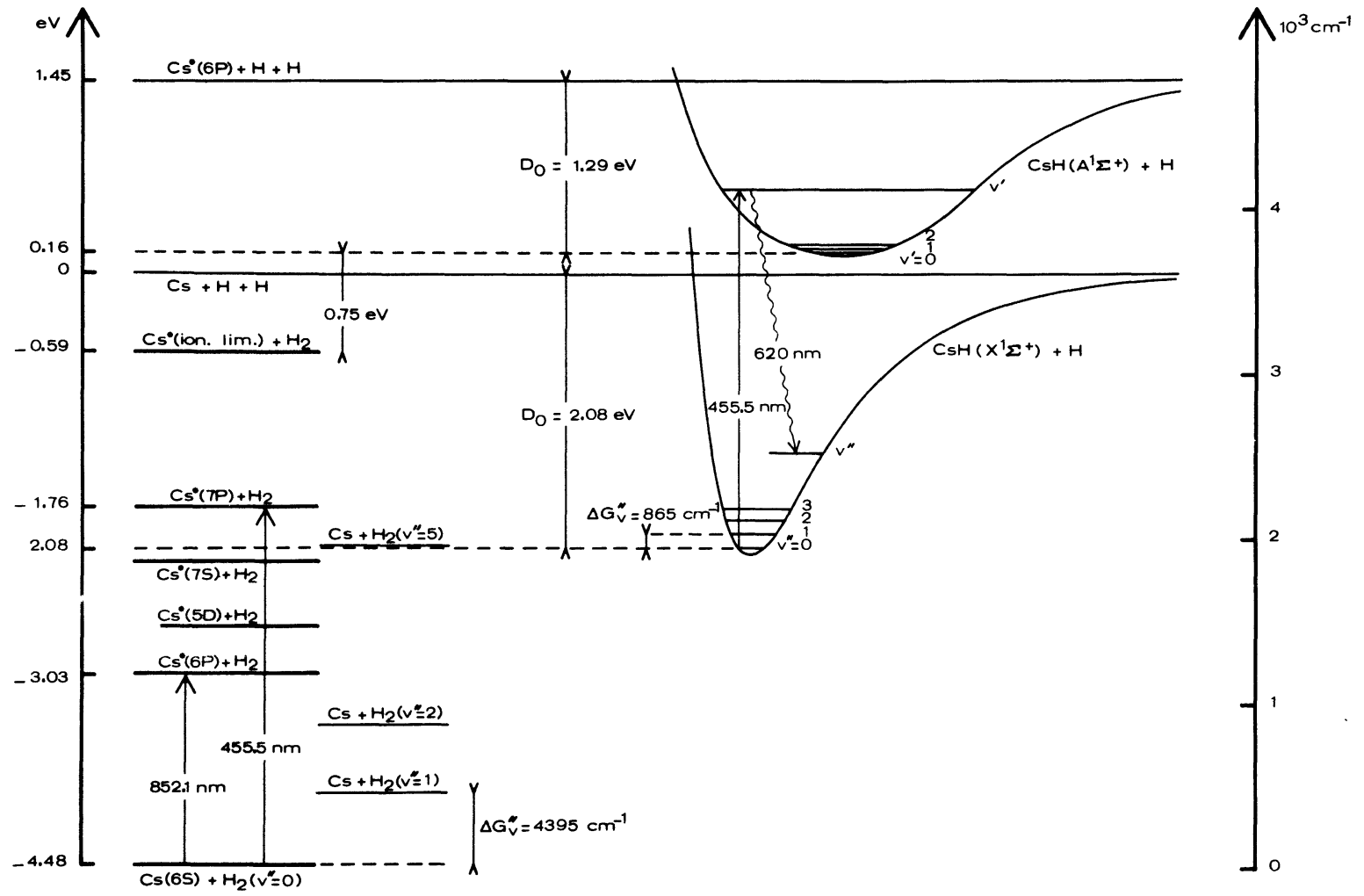

REAGENTS

PRODUCTS

Fig. 4. - Diagram of relevant energy levels in the chemical reaction $\mathrm{Cs}+\mathrm{H}_{2} \rightarrow \mathrm{CsH}+\mathrm{H}$. The right-hand part of the diagram shows the level scheme used for laser-induced fluorescence in the $\mathrm{CsH}$ molecule. 
where $n_{0}$ is the total number of Cs atoms and $\xi$ is a constant coefficient (such that $\xi I$ is the saturation parameter of the transition). In a first approximation, the rate of formation of $\mathrm{CsH}$ molecules in the ground state is given by the following equation :

$$
\frac{\mathrm{d} N(I, t)}{\mathrm{d} t}=\alpha n(I, t)-\beta N^{2}(I, t),
$$

when $\alpha$ and $\beta$ are constants. The first term in the righthand side of equation (3) holds for the production of $\mathrm{CsH}$ molecules by reactive collisions of excited $\mathrm{Cs}$ atoms with $\mathrm{H}_{2}$ molecules, whereas the second term accounts for the loss of $\mathrm{CsH}$ molecules through binary collisions leading to the formation of dimers. The steady-state solution of equation (3) gives

$$
N(I) \propto\left(\frac{\xi I}{1+\xi I}\right)^{1 / 2} .
$$

Assuming that the fluorescence signal $F$ is proportional to $N(I) \times I$, one gets

$$
F \propto \frac{I^{3 / 2}}{(1+\xi I)^{1 / 2}} .
$$

This expression yields the $I^{3 / 2}$ variation at low $I$ values, already mentioned in ref. [1] and in good agreement with our experimental observations. The asymptotic linear variation predicted by (5) for very high $I$ values, which would be obtained at saturation of the atomic transition, is expected to be unobservable with our available laser output. However, it turns out that the law (5) does not fit the experimental dependence even for intermediate intensities. Actually, the observed fluorescence grows more rapidly than $I^{3 / 2}$, in contradiction with expression (5). This seems to indicate that a non-linear process may populate excited Cs levels above the reaction threshold. Under our experimental conditions, this process could be the resonant two-photon ionization of Cs atoms via the intermediate $7 \mathrm{P}$ state, followed by electron-ion recombination $\left({ }^{1}\right)$. Note also that other one-photon processes than the direct population of the 7P level (but still resonant with the second resonance lines) may contribute to the $I^{3 / 2}$ regime observed at low intensities. One of them could be the population of higherlying levels of atomic $\mathrm{Cs}$ by inelastic collisions between two atoms in the 7P state [10].

To conclude, we have demonstrated the existence of a preferential reaction channel for the formation of $\mathrm{CsH}$ molecules (and thereby for the subsequent formation of particles), exhibiting a resonant behaviour associated with the excitation of Cs atoms to the $7 \mathrm{P}$ state. In addition, we have pointed out the possibility of other reaction channels consisting of various ways of populating higher-lying levels in atomic cesium. However, it is to be noted that, under different experimental conditions, other channels leading to formation of cesium hydride could take place. These channels would involve, e.g., electronic excitation of $\mathrm{Cs}_{2}$ molecules followed by dissociation producing excited Cs atoms [3], vibrational excitation of $\mathrm{H}_{2}$ molecules [11], reaction of $\mathrm{Cs}_{2}$ molecules with $\mathrm{H}$ atoms [12].

We intend now to further study the chemical reaction (1) by investigating the rovibrational distribution of the product $\mathrm{CsH}$ molecules by use of Fourier Transform Spectroscopy. Population distribution in the ground state will be probed by L.I.F. and absorption spectroscopy, whereas possible population of the first electronic excited state would be probed by direct spectral analysis of the chemiluminescence.

Acknowledgments. - We wish to thank Professor S. Feneuille for his interest in this work and for helpful discussions.

$\left({ }^{1}\right)$ This process has been observed to be efficient in cesium [8]. Actually, the calculated photoionization cross-section from the $7 \mathbf{P}$ state around $455 \mathrm{~nm}$ is quite large : $5.8 \times 10^{-18} \mathrm{~cm}^{2}$ [9].

\section{References}

[1] Tam, A., Moe, G. and Happer, W., Phys. Rev. Lett. 35 (1975) 1630.

[2] Omnès, R., J. Physique Lett. 41 (1980) L-63.

[3] Tam, A. C., Happer, W. and Siano, D., Chem. Phys. Le't. 49 (1977) 320.

[4] Ronn, A. M. and Earl, B. L., Chem. Phys. Lett. 45 (1977) 556.

[5] Niemax, K., Movre, M. and Pichler, G., J. Phys. B 12 (1979) 3503.

[6] TAM, A. C. and Happer, W., J. Chem. Phys. 64 (1976) 2456.

[7] HerzBerg, G., Molecular Spectra and Molecular Structure, vol. 4 (Van Nostrand-Reinhold, New York) 1979.
[8] Bréchignac, C., Cahuzac, Ph. and Débarre, A., to be published.

[9] Aymar, M., private communication."

[10] Leslie, S. G., Verdeyen, J. T. and Millar, W. S., J. Appl. Phys. 48 (1977) 4444

[11] Polanyi, J. C. and Sadowski, C. M., J. Chem. Phys. 36 (1962) 2239.

[12] Lee, Y. T., Gordon, R. J. and Herschbach, D. R., J. Chem. Phys. 54 (1971) 2410. 